\title{
The association between intimate partner domestic violence and the food security status of poor families in Brazil
}

\author{
Rita de Cássia Ribeiro-Silva ${ }^{1, *}$, Rosemeire Leovigildo Fiaccone ${ }^{2}$, Maurício Lima Barreto ${ }^{3}$, \\ Mônica Leila Portela Santana ${ }^{1}$, Sandra Maria Chaves dos Santos ${ }^{1}$, Maria Ester Pereira da \\ Conceição-Machado ${ }^{1}$ and Marie Agnès Aliaga ${ }^{3}$ \\ 'Departamento Ciência da Nutrição, Escola de Nutrição, Universidade Federal da Bahia, Av. Araújo Pinho no 32 , \\ Canela, CEP 40.1 10-150, Salvador, Bahia, Brazil: ${ }^{2}$ Departamento de Estatística, Instituto de Matemática, \\ Universidade Federal da Bahia, Salvador, Bahia, Brazil: ${ }^{3}$ Instituto de Saúde Coletiva, Universidade Federal \\ da Bahia, Salvador, Bahia, Brazil
}

Submitted 4 February 2015: Final revision received 23 July 2015: Accepted 17 August 2015: First published online 28 September 2015

\begin{abstract}
Objective: To assess the association between physical intimate partner violence and household food security within households with schoolchildren.

Design: Cross-sectional study.

Setting: Salvador, Bahia, north-eastern Brazil.

Subjects: The study was conducted in 1019 households with students. Violence between couples was evaluated using the Portuguese version of the revised Conflict Tactics Scales (CTS2), previously adapted and validated for use in Brazil. The Brazilian Food Insecurity Scale (BFIS) was used to identify food insecurity. We also obtained socio-economic information for each participant. We used multivariate Poisson regression to assess the associations of interest.

Results: According to the results of the BFIS, $62.5 \%$ of the households were found to experience food insecurity, including $19.5 \%$ moderate food insecurity and $6.5 \%$ severe food insecurity. The prevalence of minor physical violence was $9.6 \%$ (95\% CI $7 \cdot 8,11 \cdot 4 \%$ ) and of severe physical violence was $4 \cdot 7 \%$ (95\% CI 3.4, 6.0 \%) among the couples. In the final multivariate model, it was found that couples reporting minor (prevalence ratio $=1.23 ; 95 \%$ CI $1.12,1.35$ ) and severe (prevalence ratio $=1 \cdot 16$; $95 \%$ CI 1.00, 1.34) physical violence were more likely to be experiencing household food insecurity, compared with those not reporting physical violence.

Conclusions: Physical intimate partner violence was associated with food insecurity of households. The present study brings new data to the subject of the role of violence in the context of food insecurity.
\end{abstract}

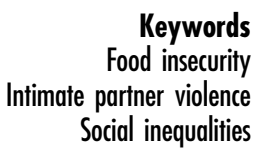

Keywords partner violence Social inequalities
According to Brazilian Food and Nutrition Security Organic Law (LOSAN-11.346/06), food and nutrition security is the realization of the right of everyone to regular and permanent access to quality food in sufficient quantity, without compromising access to other essential needs, based on health-promoting food practices that respect cultural diversity and that are environmentally, culturally, economically and socially sustainable ${ }^{(1)}$. Data from the National Household Sample Survey (PNAD), conducted by the Brazilian Institute of Geography and Statistics in 2009 using the Brazilian Food Insecurity Scale $(\mathrm{BFIS})^{(2)}$, which assesses the access dimension of food and nutrition security (i.e. food security), showed that $30 \cdot 2 \%$ of Brazilian households live in a state of food insecurity and in $5 \%$ of these cases the situation is considered severe $^{(3)}$. Not only is food insecurity associated with food availability, but it is also related to social vulnerability, which includes a combination of socio-economic, demographic and psychosocial variables ${ }^{(4)}$. As such, it leads to a reduction in the level of well-being and negatively impacts families' quality of life ${ }^{(5-8)}$.

In addition to social inequalities, domestic violence is a psychosocial element that has recently been introduced by researchers as a risk factor for food insecurity ${ }^{(4)}$. Intimate partner violence is now recognized as a major phenomenon worldwide and a serious public health issue ${ }^{(9)}$. Melchior et al. have suggested, on the one hand, that the stress generated in situations of domestic conflict causes psychological distress such as anxiety, depression and behaviour disorders, possibly compromising domestic and financial management in the family, resulting in fewer resources for planning family meals and other needs, thus contributing 
towards increasing household food insecurity ${ }^{(4)}$; and, on the other hand, food insecurity could generate depressive episodes or generalized anxiety disorder ${ }^{(10)}$.

To our knowledge, no study has assessed this association between intimate partner violence and/or psychosocial risk factors for food insecurity in Brazil. While there is compelling evidence (which will be further discussed along with the results of the present study) of associations between intimate partner violence and mental health ${ }^{(11)}$, as well as between food and nutrition insecurity and mental health ${ }^{(7,12)}$, scientific evidence of an association between intimate partner violence and household food insecurity is still limited. The hypothesis tested in the present study was that families are particularly vulnerable to food insecurity when they experience physical intimate partner violence. Considering the fact that the reduction in food availability at home tends to compromise the quality and quantity of food available especially for schoolchildren, the present study focused on household food insecurity in this group. The National Study on Food Security $^{(3,13)}$ showed that households with at least one member below the age of 18 years are more likely to experience food insecurity than households with only adults. Furthermore, the same study revealed that Bahia, a state of Northeast Brazil, has one of the highest rates of food security in the country ${ }^{(3)}$. Within this context, the objective of the present study was therefore to assess the association between physical intimate partner violence and household food security within households with schoolchildren in Bahia State, Brazil.

\section{Materials and methods}

\section{Study design and population}

This study was based on a population-based, crosssectional nutrition survey carried out from July to December 2009 in the city of Salvador, capital of the state of Bahia. Salvador is one of the most affluent cities in north-eastern Brazil, with a population of 2676606 residents ${ }^{(14)}$. The initial study evaluated the factors associated with body image dissatisfaction in adolescent students attending public schools in the city of Salvador, Brazil $^{(15)}$. The sampling process involved a complex design, structured in two stages, the first stage represented by the schools and the second by classes. To estimate the sample size, data supplied by the Bahia State Education Department for the 2007 school year, the most recent available at the time, were used. The sample was calculated on a total of 77873 students enrolled in public schools of Salvador, the capital city of Bahia. Considering a confidence level of $95 \%$ and a maximum admissible error of $2 \cdot 5 \%$, it was estimated as 1496 students for the sample. A detailed description of the sample is provided elsewhere $^{(15)}$. Of these, only 1019 students were included in the present study. This number represents those students who had been taken care of by couples that had been living together for the previous 12 months, including unmarried couples and recomposed families. Considering that the data were not initially collected for evaluating the association between physical intimate partner violence and household food insecurity, it was necessary to calculate the sample power for such association. We determined that this sample size has a statistical power of $97.0 \%$ and a significance level of 0.05 to detect the associations between food insecurity and physical intimate partner violence.

Ethical approval was provided by the Ethics Committee of the School of Nutrition, Federal University of Bahia, Brazil (approval number 002/08), and informed consent was obtained from each study participant. Considering that the study deals with situations of intimate partner physical violence and in order to protect participants, the individuals who identified themselves as the person responsible for the household, $97.4 \%$ of whom were women, were presented with the study, the informed consent document terms and the questionnaires in isolated rooms. Data collectors were trained, for two months, to deal with situations of distress caused by intimate partner violence, and women identified as likely victims were advised and referred to specialized care services such as Psychosocial Care Centers (CAPSIS).

\section{Outcome variable}

Food insecurity was measured using the BFIS. This scale has been translated, adapted and validated for the Brazilian population, key adaptations being replacing the term 'balanced meal' with 'healthy and varied diet', constructing items as questions rather than statements and ensuring that respondents understood that information would not be used to determine social programme eligibility ${ }^{(2)}$. The person responsible for taking care of the student answered the questions on food security and questionnaires were administered at school. The recall period consisted of the three months preceding the interview.

The BFIS contains fifteen items that are used to measure food security in the population. The items can be categorized into five categories: (i) psychological component (anxiety or doubt about the future availability of food in the household in order to meet the needs of its members); (ii) quality of foods (compliance with socially established food preferences and variety in the household stock); (iii) quantitative reduction of food among adults; (iv) quantitative reduction of food among children; and (v) hunger (failure to eat during a $24 \mathrm{~h}$ period due to lack of money to purchase food) ${ }^{(3)}$. Responses to these items are also used to quantify the different degrees of food insecurity experienced by families (mild, moderate and severe). In households with residents under 18 years old, whose score ranged between 0 and 15, the following cut-off points were used, according to the equidistant algorithm: 0 representing food security, $1-5$ representing 
mild food insecurity, 6-10 representing moderate food insecurity and 11-15 representing severe food insecurity. However, we collapsed these categories into food security and insecurity.

\section{Principal independent variable}

Intimate partner violence was the main independent variable of the present study, which is defined by the Centers for Disease Control and Prevention as "physical, sexual, or psychological harm by a current or former partner or spouse ${ }^{,(16)}$. However, in our study intimate partner violence was assessed using the Portuguese version of the revised Conflict Tactics Scales (CTS2) questionnaire where the definition for intimate partners included only the current partner/spouse. The CTS2 was previously adapted and validated for use in Brazil, through translation and evaluation of conceptual and item equivalences, using expert discussion groups ${ }^{(17)}$. The original instrument has five sub-scales: (i) negotiation (six items); (ii) psychological violence (eight items); (iii) physical violence (twelve items); (iv) injury (six items); and (v) sexual coercion (seven items). The items in each subscale are classified as more or less severe. Based on a former study that established an association only between the physical form of intimate partner violence and malnutrition $^{(18)}$, only the answers to the sub-scale for physical violence were used in the present study. Each question of this sub-scale is associated with one level of physical violence, namely severe or minor physical violence. The presence and level of violence were identified when there was an affirmative answer to at least one item on the sub-scale, for at least one of the members of the couple. Questionnaires were administered in the school (due to convenience to connect school and family) for respondents taking care of the students, where the majority of respondents were women (97.4\%). The respondents for the sub-scale for physical violence were the same individuals who responded to the BFIS (see above). Therefore, participants provided information on their own attitudes in conflict situations and reported, as proxies, their partner's attitudes. The results were categorized in physical violence reportedly perpetrated by the man only, by the woman only or reciprocal physical violence, each one with its minor and severe level. The recall period consisted of the twelve months preceding the interview.

\section{Potential confounding variables}

Data on the socio-economic characteristics of the participants were collected during the interviews conducted with the person responsible for taking care of the student, who was previously invited to go to the school. Interviewers were selected according to their academic and professional background and training, and their performance level was continuously checked. They administered the questionnaires and recorded the responses on a standardized form. The data collected on participants' socio-economic characteristics included four indicators: (i) the number of individuals per room in the household; (ii) the per capita monthly income; (iii) the education level of the head of the household; and (iv) the economic status of the household. Agglomeration (the number of individuals per room) was classified into $<2 \cdot 0$ (reference category) and $\geq 2 \cdot 0$; per capita monthly income (in Brazilian reais) was classified in tertiles as $<\mathrm{R} \$ 140 \cdot 00$ (dummy1), $\mathrm{R} \$ 140.00-243.57$ (dummy2) and $\geq \mathrm{R} \$ 243.57$ (reference category); and the education level of the head of the household was categorized as college or university level (reference category), 5th to 8th grade (dummy1) and $\leq 4$ th grade (dummy2). The fourth indicator included the head of family's level of education, as well as the household assets, in a broader evaluation of the household economic status. It was calculated according to the Brazilian Criteria for Economic Classification ${ }^{(19)}$. Households were grouped based on the numbers of points obtained for their assets and head of family's level of education. The cut-off points were determined by the Brazilian Criteria ${ }^{(19)}$ into best economic status (8-27 points; the reference category) and poorer economic status (0-7 points)

\section{Statistical analysis}

Epi Info version 6.04 was used to construct the database and process the data. Data were entered in duplicate, after reviewing the questionnaires and correcting any possible errors. Descriptive analyses were used to show characteristics of collected variables in the present study. We conducted univariate and multivariate Poisson regression with robust variance. Variables for adjustment were chosen in accordance with information obtained from the literature ${ }^{(20,21)}$. The magnitude of association between physical intimate partner violence and occurrence of food insecurity was described using prevalence ratios (PR) and respective $95 \%$ confidence intervals. All statistical tests were two-tailed, with a 5\% significance level. Statistical analyses were corrected according to the complex sample design, using the statistical software package STATA version 9.2. Statistical methods included the use of survey weights and of appropriate variance estimation methods for both descriptive and modelling approaches, to reflect the complex sample structure.

\section{Results}

One thousand and nineteen households were included in the present study. Although the study population had originally been selected for another study, there were no statistically significant differences in the socioeconomic characteristics of the original sample and the sub-sample used in the present study (see online 
supplementary material, Supplemental Table 1). In our study, $62.5 \%$ of the households experienced food insecurity, with three levels of severity being found: $36.5 \%$ suffering mild food insecurity, $19.5 \%$ with moderate food insecurity and $6.5 \%$ with severe food insecurity. Descriptive characteristics of the study participants are shown in Table 1.

Table 2 shows the prevalence of minor and severe physical violence perpetrated reciprocally, as well as by the women and by the men individually. The prevalence of minor physical violence was $9.6 \%$ (95\% CI 7.8, 11.4\%) and of severe physical violence was $4.7 \%$ (95\% CI 3.4, $6.0 \%)$ for reciprocal violence. There was no statistically significant difference between the prevalence rates of severe physical violence carried out by the women and by the men $(3.2 \%$ (95\% CI $2 \cdot 1,4.3 \%$ ) v. $4.3 \%$ (95\% CI 3.3 , $5.5 \%)$, respectively). The same was verified for minor physical violence $(7 \cdot 7 \%$ (95\% CI 6.1, 9.3\%) v. 7.6\% (95\% CI 6.0, 9.2\%), respectively).

In the final multivariate model adjusted for economic classification, income, agglomeration and education level, it was found that couples where at least one member reported minor $(\mathrm{PR}=1 \cdot 23 ; 95 \% \mathrm{CI} 1 \cdot 12,1.35)$ and severe $(\mathrm{PR}=1 \cdot 16 ; 95 \% \mathrm{CI} 1.00,1.34)$ reciprocal physical violence were more likely to be experiencing household food insecurity, compared with those not reporting physical violence (Tables 3 and 4).

\section{Discussion}

The objective of the present study was to evaluate the association between physical intimate partner violence and food and nutrition insecurity levels in Salvador, the capital city of the state of Bahia, Northeast Brazil. The prevalence of food insecurity found in families in Salvador (62.5\%) was higher than that reported in the results of the National Household Sample Survey (PNAD) 2004/2009 for Brazil as a whole $(30 \cdot 2 \%)$ and for many of its regions. The prevalence of food insecurity was reported as $46 \cdot 1 \%$ in the north-east of the country, $40 \cdot 3 \%$ in the north, $30.1 \%$ in the mid-west, $23.3 \%$ in the south-east and $18.7 \%$ in the south $^{(3)}$. With respect to physical intimate partner violence, in the analyses stratified by gender, results showed no significant differences between physical violence reportedly perpetrated only by women or only by men, corroborating the findings of other studies ${ }^{(22,23)}$. When analysing reciprocal intimate partner violence, the prevalence of minor physical violence identified (9.6\%) was lower than the mean found for fifteen Brazilian state capital cities $(21.5 \%)$ in previous studies ${ }^{(20)}$ that evaluated the profile of physical intimate partner violence in Brazil. A similar situation was found for severe physical violence, reported as $4.7 \%$ in Salvador compared with a mean of $12.9 \%$ for the fifteen state capital cities evaluated, with the highest prevalence being found in Belém $(22 \cdot 1 \%)^{(20)}$.

Table 1 Description of the sample, according to the study variables. Salvador, Bahia, Brazil, 2009 ( $n$ 1019)

\begin{tabular}{|c|c|c|c|}
\hline Variable & $n$ & $\%^{*}$ & $95 \% \mathrm{Cl}$ \\
\hline \multicolumn{4}{|c|}{ Per capita monthly income, shown as tertiles } \\
\hline$<\mathrm{R} \$ 140.00$ (1st tertile) & 340 & $32 \cdot 66$ & $0.28,0.36$ \\
\hline $\mathrm{R} \$ 140.00-243.57$ (2nd tertile) & 333 & $32 \cdot 38$ & $0.26,0.38$ \\
\hline$\geq \mathrm{R} \$ 243.57$ (3rd tertile) & 346 & 34.95 & $0.27,0.42$ \\
\hline \multicolumn{4}{|l|}{ Economic status } \\
\hline Better economic conditions & 539 & 53.52 & $45 \cdot 90,61 \cdot 11$ \\
\hline Worst economic conditions & 480 & $46 \cdot 47$ & $38.88,54.06$ \\
\hline \multicolumn{4}{|c|}{ Education level of the head of the family } \\
\hline$\leq 4$ th grade & 306 & 29.54 & $24.68,34.41$ \\
\hline 5th to 8 th grade & 319 & $30 \cdot 87$ & $26 \cdot 17,35 \cdot 58$ \\
\hline College or university level & 394 & 39.57 & $32 \cdot 68,46 \cdot 46$ \\
\hline \multicolumn{4}{|c|}{ Agglomeration (number of individuals per room) } \\
\hline$<2.0$ & 644 & 61.54 & $53 \cdot 32,69 \cdot 75$ \\
\hline$\geq 2 \cdot 0$ & 375 & $38 \cdot 45$ & $30 \cdot 24,46 \cdot 67$ \\
\hline
\end{tabular}

$\mathrm{R} \$$, Brazilian reais.

*The percentages shown are adjusted for the complex design of the sample.

Table 2 Severity of physical violence perpetrated by at least one member of the couple and separately for women and men. Salvador, Bahia, Brazil, 2009

\begin{tabular}{|c|c|c|c|c|c|c|c|c|c|}
\hline \multirow[b]{2}{*}{ Severity of aggression } & \multicolumn{3}{|c|}{ Couple (n 1019) } & \multicolumn{3}{|c|}{ Women (n 1019) } & \multicolumn{3}{|c|}{ Men (n 1019) } \\
\hline & $n$ & $\%$ * & $95 \% \mathrm{Cl}$ & $n$ & $\%$ * & $95 \% \mathrm{Cl}$ & $n$ & $\%$ * & $95 \% \mathrm{Cl}$ \\
\hline Severe physical violence & 48 & $4 \cdot 7$ & $3 \cdot 4,6 \cdot 0$ & 33 & $3 \cdot 2$ & $2 \cdot 1,4 \cdot 3$ & 44 & 4.3 & $3 \cdot 0,5 \cdot 5$ \\
\hline
\end{tabular}

*The percentages shown are adjusted for the complex design of the sample. 
Table 3 Analyses of multivariate associations between minor physical violence perpetrated by at least one member of the couple and food and nutrition insecurity in the study population. Salvador, Bahia, Brazil, 2009 ( $n$ 1019)

\begin{tabular}{|c|c|c|c|c|}
\hline & \multicolumn{4}{|c|}{ Food and nutrition insecurity } \\
\hline & \multicolumn{2}{|c|}{ Univariate model } & \multicolumn{2}{|c|}{ Multivariate model ${ }^{*}$} \\
\hline & PR & $95 \% \mathrm{Cl}$ & PR & $95 \% \mathrm{Cl}$ \\
\hline \multicolumn{5}{|l|}{ Minor physical violence: couple } \\
\hline No & 1.00 & Ref. & 1.00 & Ref. \\
\hline Yes & 1.32 & $1.21,1.43$ & $1 \cdot 23$ & $1.12,1.35$ \\
\hline \multicolumn{5}{|c|}{ Potential confounding variables } \\
\hline \multicolumn{5}{|c|}{ Per capita monthly income, shown as tertiles } \\
\hline$<\mathrm{R} \$ 140.00$ (1st tertile) & 4.06 & $2 \cdot 04,5 \cdot 68$ & & \\
\hline $\mathrm{R} \$ 140.00-243.57$ (2nd tertile) & 1.71 & $1 \cdot 26,2 \cdot 30$ & & \\
\hline $\mathrm{R} \$ \geq 243.57$ (3rd tertile) & 1.00 & Ref. & & \\
\hline \multicolumn{5}{|l|}{ Economic status } \\
\hline Better economic conditions & 1.00 & Ref. & & \\
\hline Worst economic conditions & 1.37 & $1.25,1.49$ & & \\
\hline \multicolumn{5}{|c|}{ Education level of the head of the family } \\
\hline$\leq 4$ th grade & 1.58 & $1 \cdot 16,2 \cdot 16$ & & \\
\hline 5th to 8 th grade & 1.46 & $1.07,1.98$ & & \\
\hline College or university level & 1.00 & Ref. & & \\
\hline \multicolumn{5}{|c|}{ Agglomeration (number of individuals per room) } \\
\hline$<2.0$ & 1.00 & Ref. & & \\
\hline$\geq 2 \cdot 0$ & $1 \cdot 22$ & $1 \cdot 11,1.34$ & & \\
\hline
\end{tabular}

$\mathrm{PR}$, prevalence ratio; $\mathrm{R} \$$, Brazilian reais; Ref., reference category.

*Multivariate model adjusted for the economic status, income, agglomeration and education level.

Table 4 Analyses of multivariate associations between severe physical violence perpetrated by at least one member of the couple and food and nutrition insecurity in the study population. Salvador, Bahia, Brazil, 2009 ( $n$ 1019)

\begin{tabular}{|c|c|c|c|c|}
\hline & \multicolumn{4}{|c|}{ Food and nutrition insecurity } \\
\hline & \multicolumn{2}{|c|}{ Univariate model } & \multicolumn{2}{|c|}{ Multivariate model* } \\
\hline & PR & $95 \% \mathrm{Cl}$ & PR & $95 \% \mathrm{Cl}$ \\
\hline \multicolumn{5}{|l|}{ Severe physical violence: couple } \\
\hline No & 1.00 & Ref. & 1.00 & Ref. \\
\hline Yes & 1.22 & $1.04,1.43$ & $1 \cdot 16$ & $1.00,1.34$ \\
\hline \multicolumn{5}{|c|}{ Potential confounding variables } \\
\hline \multicolumn{5}{|c|}{ Per capita monthly income, shown as tertiles } \\
\hline$<\mathrm{R} \$ 140.00$ (1st tertile) & 4.06 & $2 \cdot 04,5.68$ & & \\
\hline $\mathrm{R} \$ 140.00-243.57$ (2nd tertile) & $1 \cdot 71$ & $1 \cdot 26,2 \cdot 30$ & & \\
\hline$\geq R \$ 243.57$ (3rd tertile) & 1.00 & Ref. & & \\
\hline \multicolumn{5}{|l|}{ Economic status } \\
\hline Better economic conditions & 1.00 & Ref. & & \\
\hline Worst economic conditions & 1.37 & $1.25,1.49$ & & \\
\hline \multicolumn{5}{|c|}{ Education level of the head of the family } \\
\hline$\leq 4$ th grade & 1.58 & $1 \cdot 16,2 \cdot 16$ & & \\
\hline 5 th to 8 th grade & 1.46 & $1.07,1.98$ & & \\
\hline College or university level & 1.00 & Ref. & & \\
\hline \multicolumn{5}{|c|}{ Agglomeration (number of individuals per room) } \\
\hline$<2.0$ & 1.00 & Ref. & & \\
\hline$\geq 2 \cdot 0$ & $1 \cdot 22$ & $1.11,1.34$ & & \\
\hline
\end{tabular}

$\mathrm{PR}$, prevalence ratio; $\mathrm{R} \$$, Brazilian reais; Ref., reference category.

*Multivariate model adjusted for the economic status, income, agglomeration and education level.

Following the appropriate adjustments, it was found that participants reporting minor $(\mathrm{PR}=1 \cdot 23 ; 95 \% \mathrm{CI} 1 \cdot 12,1 \cdot 35)$ and severe $(\mathrm{PR}=1 \cdot 16 ; 95 \% \mathrm{CI} 1.00,1.34)$ reciprocal physical violence were more likely to be experiencing household food insecurity, compared with those not reporting physical violence. The potential confounding variables used in the analysis have been identified in several previous studies as associated with both intimate partner violence and food and nutrition insecurity ${ }^{(24-26)}$.

A review of the available literature reveals that the effect of domestic violence on food insecurity has already been explored $^{(4,10)}$, although not in Brazil. Nevertheless, the pathways through which this association develops remain unclear. Experts have reported a negative effect of 
continuous marital conflict on mental health, showing that recent victims of relationship violence have significantly higher rates of depression, anxiety, post-traumatic stress disorder, poor self-reported health, and drug and alcohol dependence, compared with individuals with no violence in their lives ${ }^{(21,27,28)}$. Moreover, depression and substance abuse may be associated with difficulty in obtaining and maintaining an adequate job, whether as a cause or effect $^{(29)}$, compromising a mother's ability to benefit from interventions, whether directed towards her employment and education or her parenting skills ${ }^{(12,30,31)}$. Controlling for the same economic variables, Casey et al. ${ }^{(12)}$ found that mothers who tested positive in a maternal depression screening were more likely to report less welfare support (adjusted $\mathrm{OR}=1.52 ; 95 \% \mathrm{CI} 1.03,2.25)$ and more household food insecurity (adjusted OR $=2 \cdot 69 ; 95 \%$ CI 2·33, 3·11) than mothers who did not test positive.

Therefore, previous research that explores the association between intimate partner physical violence or depression on one hand, and food insecurity on the other, focuses specifically on violence or depression suffered by the woman $^{(4,10)}$. However, based on the available literature, it is possible to assume that these results could be extended to reciprocal intimate partner violence, which may affect the couple's capacity to organize the domestic environment and manage the financial resources available in order to guarantee the food and nutrition security of the family. The present study findings confirm this hypothesis, justifying the focus on physical violence perpetrated by both intimate partners. This choice is also coherent with violence surveillance data, which suggest that both men and women commonly perpetrate intimate partner violence ${ }^{(32)}$. To this must be added the contributions brought by family conflict theory, which states that intimate partner violence occurs as a result of escalating conflicts, being that reciprocal intimate partner violence was associated with greater injury than was nonreciprocal intimate partner violence regardless of the gender of the perpetrator ${ }^{(23,33)}$. Reciprocity would appear to indicate that both partners are engaged in escalating the conflict, which could potentiate the burden of the effects of the violence on the physical and mental health of the individuals ${ }^{(23)}$.

The present study has limitations inherent to crosssectional studies. Specifically, because all the variables are estimated at one time point in the cross-sectional design, temporality cannot be established, resulting in the fact that the study evaluates associations rather than cause-and-effect relationships between the variables. Due to the fact that the primary study ${ }^{(15)}$ only considered students, the sample of the present study is exclusively composed of households with adolescents. However, considering that the presence of minors is an aggravating factor for our main dependent variable, i.e. food insecurity ${ }^{(13)}$, this limitation did not compromise the association of interest, as shown by the results. Another possible limitation concerns the scale used to evaluate food insecurity, which is a multidimensional and interdisciplinary phenomenon. Nevertheless, the scale is useful for estimating the prevalence of the various levels of food insecurity, to identify groups or populations at risk at local, regional or national levels, and to study the determinants and consequences of food insecurity when the appropriate indicators are added to $\mathrm{it}^{(34)}$. Because of operational issues, it was mostly the woman who answered the questions on violence between the couple. A possible tendency of the female respondents to overestimate the violence committed by the partner and also at the same time underestimate their own acts of violence may constitute another limitation of the study. However, focusing on violence perpetrated by the couple may reduce any possible bias $^{(20)}$. In addition to these limits, and even though it makes sense to first investigate the association between food insecurity and other factors in households that are particularly vulnerable to food security having children below 18 years of age, further studies could focus on such association between intimate partner violence and food insecurity in households that do not include an adolescent school student. Various characteristics that were potentially of interest in composing the factors associated with food insecurity could not be evaluated, since they were not associated with the objectives of the primary study and therefore the data had not been collected. In particular, some characteristics associated with the mental health of the subjects or with drug and alcohol dependence need to be examined in future studies. Finally, food insecurity may result from depression, loss of financial support or food stamps, and violence and other factors, each directly and independently or indirectly associated in a multifactorial causal pathway. Longitudinal studies will be required to understand more about these causal pathways.

Despite these limitations, the present study brings new data to the subject of the role of physical intimate partner violence in the situation of food insecurity. It is hoped that the data generated in the present study may prove useful by providing a foundation for the formulation of familytargeted public policies, introducing an approach that includes physical intimate partner violence among other psychosocial factors as elements that affect food insecurity levels in the country. Furthermore, the need to reduce food insecurity is indisputable. Children and families need secure access to food and benefits derived from income support and nutritional aid programmes that can potentially be addressed through public policies.

\section{Acknowledgements}

Financial support: This work was supported by the Fundação de Amparo à Pesquisa do Estado da Bahia (FAPESB; project numbers 7638/2009 and RED 0005/2014). The funder had no role in the design, analysis or writing of this article. Conflict of interest: None. Authorship: R.d.C.R.-S., M.E.P.d.C.-M. and M.L.P.S. participated in the study design, data collection, interpretation of the results and writing of the manuscript. M.L.B., M.A.A. and 
S.M.C.d.S. participated in interpretation of the results and revision of the manuscript. Ethics of buman subject participation: Ethical approval was provided by the Ethics Committee of the School of Nutrition, Federal University of Bahia, Brazil (approval number 002/08) and informed consent was obtained from each study participant.

\section{Supplementary material}

To view supplementary material for this article, please visit http://dx.doi.org/10.1017/S1368980015002694

\section{References}

1. Sistema Nacional de Segurança Alimentar e Nutricional (2010) SISAN: Diagnostico de implantação no âmbito estadual. Brasília: Coordenação Geral de Apoio a Implantação do SISAN, Ministério do Desenvolvimento Social e Combate a Fome.

2. Perez-Escamilla R, Segall-Correa AM, Kurdian Maranha L et al. (2004) An adapted version of the US Department of Agriculture Food Insecurity module is a valid tool for assessing household food insecurity in Campinas, Brazil. J Nutr 134, 1923-1928.

3. Instituto Brasileiro de Geografia e Estatística (2010) Pesquisa Nacional por Amostra de Domicílios: Segurança Alimentar 2004/2009. Rio de Janeiro: IBGE; available at http://www.ibge.gov.br/home/estatistica/populacao/segur anca_alimentar_2004_2009/tabelas_pdf

4. Melchior M, Caspi A, Howard LM et al. (2009) Mental health context of food insecurity: a representative cohort of families with young children. Pediatrics 124, e564-e572.

5. Furness BW, Simon PA, Wold CM et al. (2004) Prevalence and predictors of food insecurity among low-income households in Los Angeles County. Public Health Nutr 7, 791-794.

6. Gubert MB, Benicio MH, da Silva JP et al. (2010) Use of a predictive model for food insecurity estimates in Brazil. Arch Latinoam Nutr 60, 119-125.

7. Anderson LC, Tegegn A, Tessema F et al. (2012) Food insecurity, childhood illness and maternal emotional distress in Ethiopia. Public Health Nutr 15, 648-655.

8. Marin-Leon L, Francisco PM, Segall-Correa AM et al. (2011) Household appliances and food insecurity: gender, referred skin color and socioeconomic differences. Rev Bras Epidemiol 14, 398-410.

9. Krug EG, Dahlberg LL, Mercy JA et al. (2002) World Report on Violence and Health. Geneva: WHO.

10. Whitaker RC, Phillips SM \& Orzol SM (2006) Food insecurity and the risks of depression and anxiety in mothers and behavior problems in their preschool-aged children. Pediatrics 118, e859-e868.

11. Ayub M, Mushtaq I, Mushtaq S et al. (2013) Domestic violence, mental illness and suicidal ideation - a study from Lahore, Pakistan. J Ment Health 22, 474-481.

12. Casey P, Goolsby S, Berkowitz C et al. (2004) Maternal depression, changing public assistance, food security, and child health status. Pediatrics 113, 298-304.

13. Radimer KL, Olson CM, Greene JC et al. (1992) Understanding hunger and developing indicators to assess it in women and children. $J$ Nutr Educ 24, Suppl. 1, S36-S44.

14. Brazilian Institute of Geography and Statistics (2010) Brazilian Census 2010. http://www.ibge.gov.br/home/estatística/ população/censo (accessed May 2015).

15. Santana ML, Silva RdC, Assis AM et al. (2013) Factors associated with body image dissatisfaction among adolescents in public schools students in Salvador, Brazil. Nutr Hosp 28, 747-755.
16. National Center for Injury Prevention and Control, Division of Violence Prevention (2015) Intimate Partner Violence: Definitions. Atlanta, GA: Centers for Disease Control and Prevention; available at http://www.cdc.gov/violenceprevention/intimatepartnerviolence/definitions.html\#clarificatio

17. Moraes CL, Hasselmann MH \& Reichenheim ME (2002) Portuguese-language cross-cultural adaptation of the Revised Conflict Tactics Scales (CTS2), an instrument used to identify violence in couples. Cad Saude Publica 18, 163-176.

18. Silva RdCR, Assis AMO, Hasselmann MH et al. (2012) Influência da violência familiar na associação entre desnutrição e baixo desenvolvimento cognitivo. J Pediatr (Rio J) 88, 149-154.

19. Associação Brasileira de Empresas de Pesquisa (2008) Critério de Classificação Econômica Brasil 2008. http://www.abep.org. $\mathrm{br} /$ novo/Content.aspx?ContentID=302 (accessed July 2014).

20. Reichenheim ME, Moraes CL, Szklo A et al. (2006) The magnitude of intimate partner violence in Brazil: portraits from 15 capital cities and the Federal District. Cad Saude Publica 22, 425-437.

21. Thompson MP, Kaslow NJ, Kingree JB et al. (2000) Partner violence, social support, and distress among inner-city African American women. Am J Community Psychol 28, 127-143.

22. Anacleto AJ, Njaine K, Longo GZ et al. (2009) Prevalence of intimate partner violence and associated factors: a population-based study in Lages, Santa Catarina State, Brazil, 2007. Cad Saude Publica 25, 800-808.

23. Whitaker DJ, Haileyesus T, Swahn M et al. (2007) Differences in frequency of violence and reported injury between relationships with reciprocal and nonreciprocal intimate partner violence. Am J Public Health 97, 941-947.

24. de Souza Bittencourt L, Chaves dos Santos SM, de Jesus Pinto E et al. (2013) Factors associated with food insecurity in households of public school students of Salvador City, Bahia, Brazil. J Health Popul Nutr 31, 471-479.

25. Kaukinen CE \& Powers RA (2015) The role of economic factors on women's risk for intimate partner violence: a cross-national comparison of Canada and the United States. Violence Against Women 21, 229-248.

26. Capaldi DM, Knoble NB, Shortt JW et al. (2012) A systematic review of risk factors for intimate partner violence. Partner Abuse 3, 231-280.

27. Hill TD, Mossakowski KN \& Angel RJ (2007) Relationship violence and psychological distress among low-income urban women. J Urban Health 84, 537-551.

28. Lewis CS, Griffing S, Chu M et al. (2006) Coping and violence exposure as predictors of psychological functioning in domestic violence survivors. Violence Against Women 12, 340-354.

29. Harry E (2014) Stress and the healthcare worker. As complicated or as simple as fear and hope. J Med Pract Manage 30, 28-30.

30. Hesselink AE, van Poppel MN, van Eijsden M et al. (2012) The effectiveness of a perinatal education programme on smoking, infant care, and psychosocial health for ethnic Turkish women. Midwifery 28, 306-313.

31. Hutcheson JJ, Black MM, Talley M et al. (1997) Risk status and home intervention among children with failure-to-thrive: follow-up at age 4. J Pediatr Psychol 22, 651-668.

32. Archer J (2000) Sex differences in aggression between heterosexual partners: a meta-analytic review. Psychol Bull 126, 651-680

33. Straus MA \& Gelles RJ (1988) Violence in American families: how much is there and why does it occur? In Troubled Relationships, pp. 141-162 [EW Nunnally, C Chilman and FM Cox, editors]. Newbury Park: CA: SAGE; available at http://pubpages.unh.edu/ mas2/IPV-Methods.htm

34. Kepple AW \& Segall-Correa AM (2011) Conceptualizing and measuring food and nutrition security. Cien Saude Colet 16, 187-199. 